\title{
Expanding our views of science education to address sustainable development, empowerment, and social transformation
}

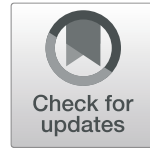

William C. Kyle Jr.(1)

\begin{abstract}
On 25 September 2015, the UN General Assembly adopted a resolution, which took effect 1 January 2016, to transform the world to better meet human needs and the requirements of economic transformation, while protecting the environment, ensuring peace and realizing human rights. Since 1987, there have been several global initiatives oriented toward sustainable development, yet science educators have often remained silent with respect to ensuring the goals of science education are linked intrinsically to the central tenets of sustainable development. Why such silence? Where are the voices of science educators?

In this position statement, I offer a rationale for expanding our views of science education to address sustainable development, empowerment, and social transformation. Science education ought to be a primary vehicle for addressing the current and emerging global challenges facing humanity. All too often, science educators merely focus upon fostering awareness and concern for global challenges. Such an orientation falls short of the education discourse that ought to be oriented toward addressing the goals, aspirations, desires, and needs of youth, who presently number 1.8 billion and represent the largest segment of the global population being underserved. The active engagement of youth in sustainable development efforts is imperative to achieve the goals of the 2030 Agenda. Youth are not mere beneficiaries of the 2030 Agenda; they have a critical role in the implementation of the Sustainable Development Goals (SDGs).

I offer a rationale for why science educators ought to become active agents in facilitating the engagement of youth in addressing global challenges facing humanity. Youth are demanding action; science educators ought to enable learners and communities to transform and reinvent the world they are inheriting.
\end{abstract}

Keywords: Sustainable development, Global challenges, Environmental education

Herein I challenge the decades honored curricular focus upon universalism and standardization. The imposition of standards and accountability - within the context of science teaching and learning - represents the antithesis of what an education in the sciences ought to be. I wish to focus on the 2030 Agenda for Sustainable Development (United Nations, 2015a), in the context of current and emerging global challenges, and the need to transform education. With this focus in mind, I draw attention to the fact that the present generation of youth (between the ages of 10 and 24) numbers 1.8 billion, which is approximately $24 \%$ of the global population

Correspondence: bill_kyle@umsl.edu

E. Desmond Lee Family Professor of Science Education, College of Education, University Missouri - St. Louis, St. Louis, MO 63121-4499, USA
(The Commonwealth, 2016; UNFPA, 2014a). ${ }^{1}$ In addition, the largest segment of the global population being underserved is youth (UNFPA, 2014a), with 90\% of the global youth population living in less developed countries (LDCs).

The importance of population dynamics for sustainable development is at the center of the post-2015 development agenda (UNFPA, 2014b). It is imperative that national development plans consider shifts in youth

\footnotetext{
${ }^{1}$ Organizations use varying age ranges for the global youth population. For example, The United Nations reports there are 1.2 billion youth aged 15 to 24 years, accounting for $16 \%$ of the global population (United Nations, 2018). While the age ranges considered to be youth vary by organization, the population and percentage of the global population are commensurate with the age ranges.
} 
population dynamics. By 2050, action is needed on environmental issues, climate change, and biodiversity; and, significant investment is needed in education / literacy, health care and nutrition, addressing poverty alleviation and hunger, decreasing under- and un-employment, and enhancing food production / productivity. The World Youth Report on Youth and the 2030 Agenda for Sustainable Development examines the mutually supportive roles of the new agenda and current youth development efforts (United Nations, 2018). Youth are not mere beneficiaries of the 2030 Agenda, rather they have a critical role in the implementation of the Sustainable Development Goals (SDGs). The active engagement of youth in sustainable development efforts will be imperative to achieving the goals of the 2030 Agenda.

Science educators ought to be at the forefront of ensuring the education discourse is oriented toward the goals, aspirations, desires, and needs of all 1.8 billion youth versus adhering to a bureaucratic characterization of science in which universal standards, goals, objectives, and accountability measures are imposed upon learners, teachers, and administrators by policy makers and politicians. All too often, as a result of universalism and standardization, learners experience an education in science disassociated from the contextual realities of life.

The United Nations Development Programme (UNDP), the United Nations Population Fund (UNFPA), the United Nations Children's Fund (UNICEF), and the United Nations Entity for Gender Equality and the Empowerment of Women (UNWomen) all commit to collaborate to deliver on the 2030 Agenda for Sustainable Development (UNFPA, 2017). Their underlying principle is 'leaving no one behind' and 'reaching the furthest behind'. In compliance with their respective mandates, they will focus upon such key areas as: "(a) Eradicating poverty; (b) Addressing climate change; (c) Improving adolescent and maternal health; (d) Achieving gender equality and the empowerment of women and girls; (e) Ensuring greater availability and use of disaggregated data for sustainable development" (p. iii).

Gro Harlem Brundtland, in the Prologue to the first quadrennial Global Sustainable Development Report (Independent Group of Scientists appointed by the Secretary-General, 2019), notes the adoption of the Sustainable Development Goals "was a key moment in building a consensus for urgent, inclusive action" (Brundtland, 2019, p. xv). She states:

Today, faced with the imperative of tackling climate change and responding to radical, fast-paced shifts in global technology, consumption and population patterns, there is growing consensus that sustainable development is the only way that we can avert environmental and social disaster. (Brundtland, 2019, p. $\mathrm{xv}$ )
Further, she asserts the implementation of the SDGs "offers a pathway to a world where poverty, inequality and conflict will not blight the life chances of millions of people who are currently denied the opportunity to enjoy their fundamental rights and freedoms" (Brundtland, 2019, p. xv).

The Independent Group of Scientists appointed by the Secretary-General (2019) assert:

The challenge of achieving sustainable development is to secure human well-being in ways that are not only safe, in terms of not threatening the Earth system with irreversible change, but also just. Ultimately then, sustainable development should be pursued in the spirit of finding pathways that enable a good life for all, leaving no one behind, while safeguarding the environment for future generations and ensuring planetary justice. (p. 2)

The authors consider "how science can best accelerate the achievement of the Sustainable Development Goals" and they argue "in favour of a sustainability science as a new way for science to contribute directly to sustainable development (p. 2). The Report presents a scientific view on integrated ways to accomplish the transformation of the planet. The authors identify six essential entry points, where the interconnections across the SDGs and targets are suitable for accelerating the necessary transformation. The six entry points are:

- Strengthening human well-being and capabilities;

- Shifting towards sustainable and just economies;

- Building sustainable food systems and healthy nutrition patterns;

- Achieving energy decarbonization with universal access to energy;

- Promoting sustainable urban and peri-urban development; and

- Securing the global environmental commons.

Considering these global initiatives, where are the voices of science educators? I assert we must expand our views of science education to address sustainable development, empowerment, and social transformation, thereby ensuring an informed, ecologically / environmentally literate, thoughtful, and empathetic citizenry. Empowerment - particularly in LDCs - is correlated with poverty alleviation, addressing inequality, and economic growth. An education in science must be contextualized and connected to the life world experiences of learners, while taking into consideration issues of placebased locality, as well as social, civic, and cultural values.

\section{Background}

Prior to the 1960s, the philosophy of science was dominated by the writings of the logical empiricists, whom 
Habermas (1972) regarded as presenting a 'scientistic misconception' of science. Historically, science educators perceived of themselves as being more aligned with science than with education. Science courses - from elementary school through undergraduate studies - were structured and taught from the perspective of an uncritical acceptance of logical positivism and, to a large extent, as a mastery of abstract concepts and principles, rarely connected to real life experiences (Kyle Jr., 2006; Onwu, 2000; Onwu \& Kyle Jr., 2011). All too often, science educators neglected to acknowledge the differences in style, subject matter, rhetoric, and results between the natural sciences and the human studies (see Habermas, 1972).

By adopting an image of science teaching and learning focused upon a historical bent, it was expected students would learn about the great discoveries of the past, rather than the practices of present-day scientists. Early science educators failed to recognize how postempiricist philosophy - that is, the repudiation of the idea that science and knowledge can be grounded in theory neutral observations - revealed just how closely traditional interpretations of knowledge were connected to an understanding of power and of the relation between power and knowledge (see Marsonet, 2016, 2018; Oldroyd, 1986).

To the present day, the link between science and realworld experiences is almost always tenuous in the minds of learners. The lack of curricular connections between science and learners' day-to-day lived experiences obscures and diminishes the relevance of science in their lives. Scientific practices are political in ways central to their epistemic success (see Brown \& Malone, 2004). Fischer (1998) notes sociological research has documented the extent to which science is as much a socio-cultural activity as a technical enterprise. He asserts full understanding of scientific findings is incomprehensible apart from the socio-cultural settings, which offer purpose and meaning. Thus, students - and citizens alike - have been denied access to this essential feature of science; they have been led to reconstruct the development of science as a steady accumulation of results with the supporting evidence. In general, students - and ultimately the general citizenry - have been deprived of the opportunity to experience the shifts in interests that have marked the history of science. Devoid of the social and political processes of science, the science curriculum epitomized a single, collective, consistent account of the progression of science. This is true with respect to environmental science as well, an interdisciplinary academic field that learners seldom experience in the context of their school-based science education.

The origin of environmental science, and subsequently environmental education, can be traced to the 1960s.
The environmental movement and environmental education (EE) arose as a result of public awareness. In the US, and many developed nations, Rachel Carson's (1962) Silent Spring inspired the public's interest and engagement with environmental issues. These fields emerged based upon the need for interdisciplinary studies to analyze emerging environmental issues and concerns. During this same period, primarily in Western developed countries, environmental laws and protections were being passed, leading to a heightened awareness among the public to such issues. The laws were wide ranging, focusing upon such issues as: air and water quality; waste management and contaminant cleanup; water, mineral, and forest resource management; and biodiversity protection. Environmental laws are part of the fabric of most nations, as well as the basis of international law and treaties.

It should be noted, however, the current Trump Administration in the US was the first to not name a science advisor since 1941. It was nearly 2 years into the Administration before the US Senate confirmed a director of the White House Office of Science and Technology Policy on 2 Jan 2019. The Administration's distrust of academic, peer-reviewed science and science advisors imperils domestic US policy, as well as the ability of the US to engage internationally on science-related matters of global importance, especially regarding issues related to sustainable development and the environment. With respect to environmental issues, the Trump Administration consistently places politics ahead of public health and survival of the planet (Kyle Jr, 2019). This is evidenced by the Administration pulling out of international accords, such as the Paris Climate Agreement, an agreement within the United Nations Framework Convention on Climate Change (UNFCCC) that focuses upon greenhouse-gas-emissions mitigation, adaptation, and finance; or through the reversal of more than 80 environmental rules and regulations (see Harvard Law School Environmental \& Energy Law Program, 2019; Sabin Center for Climate Change Law, 2019).

Youth should not be disenfranchised in their educational opportunities due to poor political leadership. Rather, science educators ought to facilitate ways for youth to express their political agency. O'Brien, Selboe, and Hayward (2018) highlight diverse ways in which youth are challenging power relationships and political interests to promote climate-resilient futures.

\section{Sustainable development, environmental education and global challenges}

The focus herein is upon sustainable development - inclusive of, but not limited to, environmental education and environmental issues. For me, the broader concept of sustainable development addresses the global 
consideration of the perspective of education for the development of responsible societies (see Sauvé, 1996). Sauvé notes "responsible development, which must be defined contextually, becomes the guarantee of a type of sustainability deliberately chosen by the community" (p. 29). It is this place-based orientation that enables educators to focus upon sustainable development, empowerment and social transformation in ways meaningful and relevant to the current generation of youth. The 17 Global Goals for Sustainable Development (United Nations, 2015a) offer a starting point for educators to begin to collaborate with youth, schools, and communities and initiate a research agenda that should extend well beyond 2030 in order to ensure progress is made toward addressing and achieving the SDGs. Learning opportunities must be transformed to ensure the active engagement of youth and communities in the context of experiential learning (see Eyler, 2009; Kolb, 1984; Shulman, 2002). Educators ought to be purposefully engaging with learners in direct experience and focused reflection to increase knowledge, develop skills, clarify values, and develop the capacity of learners to contribute to their communities. Experiential education methodologies include, but are not limited to, informal/free-choice learning, service learning, internships, field experiences, and project-based/problem-based learning.

An orientation focusing upon the SDGs would be more relevant for the many cultures that do not possess a term for the environment (Strathern, 1980). Many local languages do not have a word for the phenomenon environment; or, for such issues as climate change and biodiversity. DeLoughrey, Didur, and Carrigan (2015) note such cultures "ethical and philosophical codes are not simply assimilable to the binaries of western knowledge configurations" (p. 11). In addition, EE often promotes the dominant Western cultural values of an idealized nature (Low, Taplin, \& Scheld, 2005). The dominant cultural narrative espouses a universal conception of how individuals ought to interact with the environment and fails to reflect social and cultural diversity. The processes of cultural hegemony - the dominance of one cultural group's ideology and values over another's - in the context of EE, encourages a paradigm of proenvironmental behaviors (PEBs). PEBs is defined by Kollmuss and Agyeman (2002) as "behavior that consciously seeks to minimize the negative impact of one's actions on the natural and built world" (p. 240). However, identifying behaviors to change and evaluating the effects of interventions, the focus of much scholarship in environmental psychology (see Steg \& Vlek, 2009), fails to address the totality of the societal transformations necessary to address sustainable development and fails to acknowledge the need for the place-based contextual reality of such transformations. Kurisu (2015) advances the field of PEBs, from the origins in developed countries focused upon limited target behaviors, to address issues in developing countries, offering practical academic tools for analyzing environmental behaviors.

The most comprehensive compilation of work in the field of environmental education is the International Handbook of Research on Environmental Education, edited by Stevenson, Brody, Dillon, and Wals (2013). The Handbook illuminates the important understandings developed by EE research, critically examines the ways in which the field has changed over the decades, articulates the current debates and controversies, explicates what is still missing from the EE research agenda, and foreshadows where the agenda might and could be headed in the future. Stevenson, Wals, Brody, and Dillon (2013) note EE:

Has received considerably more attention in recent years as contested notions of environment and sustainability have become common topics of conversation among the public, the subject of media interest, and the focus of much political debate and legislation. Systemic linkages between environment, health, climate, poverty, development, and education have become more widely accepted as the years have passed. (p. 8)

However, despite the history of EE, it is not embedded or woven into the typical school curricula. EE is often avoided in school-based settings due to negative emotions and the overwhelming sense of hopelessness students and educators often feel as a result of immersing into such issues. Such perceptions are evidenced in the political discourse and media-covered hot topics; skepticism of science is rampant in conjunction with negative feelings constructed from science education. Hope and empowerment seem to be drivers for connecting environmental issues with environmental responsibility (Wilks \& Harris, 2016).

David Suzuki, an outspoken leader in ecological sustainability, summarized the difference between transformative environmental education within science education in an interview with Farley Mowat (1990) as follows:

My sense of injustice at what human beings were doing to the living world didn't suddenly happen. It was a gradual understanding that science is fundamentally flawed because scientists focus on parts of nature and study these in isolation from the rest. (pp. 173-174)

In other words, aspects of science education focus on facts that compartmentalize the scientist from the big 
picture and the daily lived experiences of students. In the typical classroom, students are often immersed with facts, vocabulary and laboratory activities, without the opportunity to connect their learning to the potential impact of daily choices to the environment. Thus, EE may inadvertently continue to separate new findings and science knowledge from its application in everyday life, sometimes even ignoring or rejecting the critical need for assimilation of knowledge into behavior changes (Chinn \& Brewer, 1993). This is particularly true with respect to the global challenges confronting the present and future generations of youth.

Presently, the global population uses resources at a rate $40 \%$ faster than the planet can regenerate in a calendar year. As recently as around 1980, humanity's demand for ecological resources - the Ecological Footprint - was congruent with the planet's biocapacity - the amount of ecological resources Earth is able to generate that year (Earth Overshoot Day, 2019, About Earth Overshoot Day, section 1 1). In essence, in the course of about 40 years, we have seen a shift to a situation where we increasingly overspend the ecological resources at a faster and faster rate (the status in 1980 did not imply equitable consumption of resources, as some nations used a lot less and some used a lot more; this is certainly true today as well). In 2019, Earth Overshoot Day was reached on July 29th. If we continue with a business-asusual lifestyle and do not begin to make significant changes, then around the time children born in 2019 graduate from high school Earth Overshoot Day will arrive well before July 1st. What this means is in the mid2030s it would take 2+ years for Earth to regenerate what is used in one year. Reaching this level of ecological deficit spending may be physically impossible (Ewing et al., 2008; Wackernagel, 2008).

Thus, over the course of the next 15 years, between now and the mid-2030s, a different kind of community of practice in science classrooms is going to have to emerge. The world is facing almost insurmountable challenges. These challenges transcend national boundaries. The Millennium Project identified 15 Global Challenges Facing Humanity that "provide a framework to assess the global and local prospects for humanity" (Glenn, Gordon, \& Florescu, 2009, p. 10). Our ability to provide life's essentials, for an ever-expanding human population and within the carrying capacity of supporting ecosystems, will require major advances in science and technology and a scientifically literate citizenry. Glenn, Gordon, and Florescu (2011) assert:

The world has the resources to address its challenges. What is not clear is whether the world will make good decisions fast enough and on the scale necessary to really address the global challenges. Hence, the world is in a race between implementing everincreasing ways to improve the human condition and the seemingly ever-increasing complexity and scale of global problems. (p. 2)

\section{Transforming our vision of education}

Given the urgent need for humanity to generate and implement effective responses to current challenges, there is recognition among governments that fundamental reordering of global priorities is needed in order to implement the goals of sustainable development. The term sustainable development was initially conceptualized in a report entitled Our Common Future, referred to as the Brundtland Report, from the United Nations World Commission on Environment and Development (WCED, 1987). The document states:

Sustainable development is development that meets the needs of the present without compromising the ability of future generations to meet their own needs. It contains within it two key concepts:

- the concept of 'needs', in particular the essential needs of the world's poor, to which overriding priority should be given; and

- the idea of limitations imposed by the state of technology and social organization on the environment's ability to meet present and future needs. (The Concept of Sustainable Development section, $\mathbf{g} 1)$

We have witnessed 30+ years of UN declarations, agreements and reports, in which successes and gaps in achieving goals are reported and calls for future action are asserted. A brief overview of the history of these initiatives follows, accompanied by my own personal assertion that after over 30 years it is imperative to transform our vision of education.

The notion of fundamentally reordering global priorities was first enshrined in the Declaration of the Earth Summit in Rio de Janeiro (Brazil) in 1992. Ten years later, when the World Summit on Sustainable Development (WSSD) convened in Johannesburg (South Africa), it was hardly a point of dispute acknowledging not much progress had been made at the level of local communities for most global environmental issues (United Nations, 2002). With poverty deepening and becoming more widespread, and environmental degradation of essential ecosystems worsening, questions arose whether the subsequent actions and recommendations of the World Summit would be able to contribute in meaningful and realistic ways to achieving sustainable development.

In 2000, the Millennium Summit put forth an agreement to help developing countries attain what were later 
codified as the Millennium Development Goals (MDGs). The eight MDGs became the overarching framework for developing countries for 15 years. In the summative report (United Nations, 2015b), the dual reality of 15 years of development efforts was characterized as follows: "unprecedented efforts have resulted in profound achievements" (p. 4) and "despite many successes, the poorest and most vulnerable people are being left behind" (p. 8).

On 25 September 2015, the UN General Assembly adopted a resolution, which took effect 1 January 2016, to "stimulate action over the next 15 years in areas of critical importance for humanity and the planet" (United Nations, 2015a, Preamble, 44). Entitled Transforming our world: The 2030 Agenda for Sustainable Development offers a plan to transform the world to better meet human needs and the requirements of economic transformation, while protecting the environment, ensuring peace and realizing human rights. The agenda includes 17 Sustainable Development Goals (SDGs) and 169 targets, which build upon the MDGs and strive to complete what was not achieved in the previous 15 years. The 17 SDGs are not legally binding; countries should assume ownership and establish a national framework for achieving the goals (see, http://www.un.org/sustainabledevelopment/sustainable-development-goals/). While the MDGs were intended for action in developing countries only, the 17 SDGs apply to all countries.

Since the inception of the concept of sustainable development $30+$ years ago, many governments, agencies, NGOs, and citizens have been engaged in efforts to improve the lives of people and protect the planet. Yet, I raise the following questions: Why have there been so few efforts to transform schooling to ensure the goals of science education are linked to the central tenets of sustainable development? Why are the 15 Global Challenges Facing Humanity, the 8 Millennium Development Goals, the 17 Sustainable Development Goals, and the notion of Earth Overshoot Day not a part of the discourse of every citizen on the planet? If we hope citizens will engage in deliberation and action-taking around the most significant issues confronting humanity, then we should expand our views of the goals of education to address sustainable development, empowerment, and social transformation.

Sachs (2015) asserts "sustainable development is a way to understand the world as a complex interaction of economic, social, environmental, and political systems" (p. 11). I pose the following questions: Where in the standard curriculum do students construct such understandings? In what ways should education be more intrinsically linked to issues of sustainable development? I suggest a response to these questions ought to begin by ensuring education is more relevant to the needs of learners, communities, and society. Sachs further asserts sustainable development is "a way to define the objectives of a well-functioning society, one that delivers wellbeing for its citizens today and for future generations" ( $p$. 11).

Traditionally, literacy is framed in terms of students' learning disciplinary knowledge from the past. Such a perspective fails to capture dynamic aspects of the emergence / disappearance of new literacies. Among science educators, van Eijck (2009) offers the notion of scientific literacy as an emergent feature of collective praxis. This notion is "grounded in a conception of knowledge as a collective and distributed cognitive entity" (p. 255). He notes "grounding the concept of scientific literacy in a cultural-historical perspective allows the articulation of what being scientifically literate means" (p. 256). Stevenson and Dillon (2010) emphasize the importance of engaging learners as active agents. Meaningful learning about and informed action on environmental issues requires critical inquiry and reflection, as well as imagination to generate possibilities for creating more sustainable socio-ecological practices, and action to ameliorate current environmental concerns. They highlight the challenges and complexity of engaging youth and adults in meaningful learning.

Onwu and Kyle Jr. (2011) state if we wish to integrate the goals of sustainable development into science education, then there is a need to expand our view of the goals of science education beyond the content and process aims of science teaching and learning. What is needed is a shift of emphasis of science education from one bound by disciplines and subject matter headings - from learning science as a body of knowledge - to learning science linked to contextual realities of life and living. There is a need to recognize the challenge of sustainable development is not universal, but rather context dependent. And, as noted above, youth should no longer be viewed as mere beneficiaries of education; they ought to be viewed as having a critical role in the transformation of education and society, as well as in the implementation of the SDGs. The 1.8 billion youth / adolescents represent the future; a future that offers new opportunities for:

- education, entrepreneurial, and skill-development initiatives;

- community development and social transformation;

- equitable and sustainable economic growth; as well as

- opportunities to address the many global challenges facing humanity.

Greene (1995) states emphatically the main point of education in the context of a lived life is "to enable a human being to become increasingly mindful with regard to his or her lived situation - and its untapped 
possibilities" (p. 182). Science is a human activity. The values of science are therefore human values. As Bronowski (1956/65) posits, the strengths of science and its safeguards rest predominantly on principles of freedom; notably, free inquiry, free thought, free speech and tolerance, all of which are the hallmarks of respect of human rights, freedom, and democracy. Learners ought to be afforded the opportunity to exercise creativity, debate, and dissent in the process of learning science. Through experiencing such an education in science, youth may acquire important insights into social change, systems change, citizenship, and democracy that many education systems are currently failing to provide (Hayward, 2012).

\section{Conclusion}

Science educators must begin to regard education as a primary means of investing in human resources. The youth of today must be able to address complex everyday issues yet unforeseen. This is not a modest goal. We must ensure all learners have access to an equitable education. There is a need to bridge the divide and facilitate dialogue between formal and informal / free-choice educators, as well as disciplinary and interdisciplinary science education researchers. Today's youth recognize the implications of failing to transform toward a more sustainable future are profound (IPCC, 2014).

Ideally learners will be afforded the opportunity to experience a more progressive education (Dewey 1990/ 1900) in the sciences, oriented toward real-world, experiential, context-based approaches to teaching and learning. In addition to challenging the notion of universalism and standardization, progressive science education will require a different form of assessment oriented toward performance observations and active assessment of learning. The goal of assessment ought to be oriented toward self- and social empowerment, action-taking, and transformation.

Throughout this article, I have raised the following questions:

- Why have there been so few efforts to transform schooling to ensure the goals of science education are linked to the central tenets of sustainable development?

- Why are the 15 Global Challenges Facing Humanity, the 8 Millennium Development Goals, the 17 Sustainable Development Goals, and the notion of Earth Overshoot Day not a part of the discourse of every citizen on the planet?

- Where in the standard curriculum do students construct the understanding that sustainable development is a way to understand the world as a complex interaction of economic, social, environmental, and political systems?
- In what ways should education be more intrinsically linked to issues of sustainable development?

On 6 May 2019, the Intergovernmental Science-Policy Platform on Biodiversity and Ecosystem Services (IPBES) released a report titled, Nature's Dangerous Decline 'Unprecedented';

Species Extinction Rates 'Accelerating'. The report assesses changes over the past five decades and asserts nature is declining globally at rates unprecedented in human history - and the rate of species extinctions is accelerating, with grave impacts on people around the world now likely. Sir Robert Watson, IPBES Chair, stated:

The overwhelming evidence of the IPBES Global Assessment, from a wide range of different fields of knowledge, presents an ominous picture. The health of ecosystems on which we and all other species depend is deteriorating more rapidly than ever. We are eroding the very foundations of our economies, livelihoods, food security, health and quality of life worldwide.

Watson further notes the report tells us:

It is not too late to make a difference, but only if we start now at every level from local to global. Through 'transformative change', nature can still be conserved, restored and used sustainably - this is also key to meeting most other global goals. By transformative change, we mean a fundamental, system-wide reorganization across technological, economic and social factors, including paradigms, goals and values.

Fundamental transformation is imperative to achieve the sustainable future articulated in the 2030 Agenda. The youth of today - and tomorrow - have the potential to transform the planet. As educators, our role ought to be to enable learners and communities to change and reinvent the world they are inheriting. We ought to strive to enhance the ability of youth and communities to work collectively toward a better society.

\footnotetext{
Abbreviations

EE: Environmental Education; IPBES: Intergovernmental Science-Policy Platform on Biodiversity and Ecosystem Services; IPCC: Intergovernmental Panel on Climate Change; LDCs: Less Developed Countries; MDGs: Millennium Development Goals; NGOs: Non-Government Organizations; PEBs: ProEnvironmental Behaviors; SDGs: Sustainable Development Goals; UNDP: The United Nations Development Programme; UNFCCC: United Nations Framework Convention on Climate Change; UNFPA: United Nations Population Fund; UNICEF: United Nations Children's Fund; UNWomen: United Nations Entity for Gender Equality and the Empowerment of Women; WCED: World Commission on Environment and Development; WSSD: World Summit on Sustainable Development
} 


\section{Authors' contributions}

The author is the sole author. The author read and approved the final manuscript.

\section{Funding}

There were no funding sources for this article.

\section{Availability of data and materials}

Not applicable. Data sharing is not applicable to this article as no datasets were generated or analyzed during the current study.

\section{Competing interests}

The authors declare that they have no competing interests.

Received: 25 May 2019 Accepted: 21 November 2019

Published online: 14 January 2020

\section{References}

Bronowski, J. (1956/1965). Science and human values, (Rev. ed., ). New York: Harper \& Row.

Brown, R., \& Malone, E. (2004). Reason, politics, and the politics of truth: How science is both autonomous and dependent. Sociological Theory, 22(1), 106-122.

Brundtland, G. H. (2019). Prologue. Independent Group of Scientists appointed by the secretary-general. Global Sustainable Development Report 2019: The Future is Now - Science for Achieving Sustainable Development (pp. xv - xvii). New York: United Nations.

Carson, R. (1962). Silent spring. New York: Houghton-Mifflin.

Chinn, C. A., \& Brewer, W. F. (1993). The role of anomalous data in knowledge acquisition: A theoretical framework and implications for science instruction. Review of Educational Research, 63(1), 1-49.

DeLoughrey, E., Didur, J., \& Carrigan, A. (Eds.) (2015). Global ecologies and the environmental humanities: Post-colonial approaches. New York: Routledge.

Dewey, J. (1990/1900). The school and society. Chicago: University of Chicago Press. (Originally published in 1900)

Earth Overshoot Day (2019). About Earth overshoot day. Retrieved December 18, 2019, from. https://www.overshootday.org/about-earth-overshoot-day/

Ewing, B., Goldfinger, S., Wackernagel, M., Stechbart, M., Rizk, S. M., Reed, A., \& Kitzes, J. (2008). The Ecological footprint atlas 2008. Oakland: Global Footprint Network.

Eyler, J. (2009). The power of experiential education. Liberal Education, 95(4), 22-26.

Fischer, F. (1998). Beyond empiricism: Policy inquiry in post positivist perspective. Policy Studies Journal, 26(1), 129-146.

Glenn, J. C., Gordon, T. J., \& Florescu, E. (2009). 2009 state of the future. Washington, DC: The Millennium Project.

Glenn, J. C., Gordon, T. J., \& Florescu, E. (2011). 2011 state of the future. Washington, DC: The Millennium Project.

Greene, M. (1995). Releasing the imagination: Essays on education, the arts, and social change. San Francisco: Jossey-Bass.

Habermas, J. (1972). Knowledge and human interests (J. J. Shapiro, Trans.). London: Heinemann (original work published in 1968).

Harvard Law School Environmental \& Energy Law Program. (2019, November). Regulatory rollback tracker. https://eelp.law.harvard.edu/regulatory-rollbacktracker/

Hayward, B. (2012). Children, citizenship and environment: Nurturing a democratic imagination in a changing world. London: Routledge.

Independent Group of Scientists appointed by the Secretary-General (2019). Global sustainable development report 2019: The future is now - Science for achieving sustainable development. New York: United Nations.

Intergovernmental Panel on Climate Change (IPPC). (2014). Climate change 2014 synthesis report: Summary for policy makers. http://www.ipcc.ch/pdf/ assessment-report/ar5/syr/AR5_SYR_FINAL_SPM.pdf

IPBES. (2019). Nature's dangerous decline 'unprecedented'; Species extinction rates 'accelerating'. IPBES Global Assessment Report on Biodiversity and Ecosystem Services. https://www.ipbes.net/news/Media-Release-Global-Assessment

Kolb, D. (1984). Experiential learning: Experience as the source of learning and development. Englewood Cliffs: Prentice-Hall.

Kollmuss, A., \& Agyeman, J. (2002). Mind the gap: Why do people act environmentally and what are the barriers to pro-environmental behavior? Environmental Education Research, 8(3), 239-260.

Kurisu, K. (2015). Pro-environmental behaviors. New York: Springer.
Kyle Jr., W. C. (2006). The road from Rio to Johannesburg: Where are the footpaths to/from science education? International Journal of Science and Mathematics Education, 4, 1-18.

Kyle Jr., W. C. (2019, November). The marginalization of science in the Trump era [Paper presentation]. Critical Questions in Education (CQiE) conference. Chicago, United States.

Low, S., Taplin, D., \& Scheld, S. (2005). Rethinking urban parks: Public space and cultural diversity. Austin: University of Texas Press.

Marsonet, M. (2016). Science and different images of the world. Academicus: International Scientific Journal, 14, 14-27.

Marsonet, M. (2018). Post-empiricism and philosophy of science. Academicus: International Scientific Journal, 16, 26-33.

Mowat, F. (1990). Rescue the earth! Conversations with green crusaders. Toronto: McCelland \& Stewart.

O'Brien, K., Selboe, E., \& Hayward, B. M. (2018). Exploring youth activism on climate change: Dutiful, disruptive, and dangerous dissent. Ecology and Society, 23(3), 42. https://doi.org/10.5751/ES-10287-230342.

Oldroyd, D. (1986). The arch of knowledge: An introductory study of the history, philosophy, and methodology of science. New York: Methuen.

Onwu, G. O. (2000). How should we educate science teachers for a changing society? South African Journal of Higher Education, 14(3), 43-50.

Onwu, G. O., \& Kyle Jr., W. C. (2011). Increasing the socio-cultural relevance of science education for sustainable development. African Journal of Research in Mathematics, Science and Technology Education, 15(3), 5-26.

Sabin Center for Climate Change Law. (2019, November). Climate deregulation tracker. https://climate.law.columbia.edu/climate-deregulation-tracker

Sachs, J. D. (2015). The age of sustainable development. New York: Columbia University Press.

Sauvé, L. (1996). Environmental education and sustainable development: A further appraisal. Canadian Journal of Environmental Education, 1, 7-34.

Shulman, L. (2002). Making differences: A table of learning. Palo Alto: The Carnegie Foundation for the Advancement of Teaching.

Steg, L., \& Vlek, C. (2009). Encouraging pro-environmental behaviour: An integrative review and research agenda. Journal of Environmental Psychology, 29, 309-317.

Stevenson, R. B., \& Dillon, J. (Eds.) (2010). Engaging environmental education: Learning, culture and agency. Rotterdam: Sense Publishers.

Stevenson, R. B., Brody, M., Dillon, J., \& Wals, A. E. J. (Eds.) (2013). International handbook of research on environmental education. New York: Routledge.

Stevenson, R. B., Wals, A. E. J., Brody, M., \& Dillon, J. (2013). Introduction: An orientation to environmental education and the handbook. In R. B. Stevenson, M. Brody, J. Dillon, \& A. E. J. Wals (Eds.), International handbook of research on Environmental education, (pp. 1-6). New York: Routledge.

Strathern, M. (1980). No nature, no culture: The Hagan case. In C. MacCormack, \& M. Strathern (Eds.), Nature, culture, and gender, (pp. 174-222). Cambridge: Cambridge University Press.

The Commonwealth (2016). Global youth development index and report 2016. London: Commonwealth Secretariet.

UNFPA (2014a). State of world population - The power of 1.8 billion: Adolescents, youth and the transformation of the future. New York: United Nations Population Fund.

UNFPA (2014b). Population dynamics in the post-2015 development agenda: Report of the global thematic consultation on population dynamics. New York: United Nations Population Fund.

UNFPA (2017). UNFPA strategic plan, 2018-2021. New York: United Nations Population Fund.

United Nations. (2002). Commission on sustainable development. The Johannesburg summit test: What will change? Available at www. johannesburgsummit.org

United Nations. (2015a). Transforming our world: The 2030 Agenda for sustainable development. Resolution A/Res/70/1. Retrieved from: http://www.un.org/ga/ search/view_doc.asp?symbol=A/RES/70/1\&Lang=E

United Nations. (2015b). The millennium development goals report 2015. New York: United Nations. Retrieved from http://www.un.org/millenniumgoals/2015 MDG_Report/pdf/MDG\%202015\%20rev\%20(July\%201).pdf

United Nations (2018). Youth and the 2030 agenda for sustainable development. New York: United Nations.

van Eijck, M. (2009). Scientific literacy: Past research, present conceptions, and future developments. In W.-M. Roth, \& K. Tobin (Eds.), Handbook of research in North America, (pp. 245-258). Rotterdam: Sense Publishers. 
Wackernagel, M. (2008). Forward. In B. Ewing, S. Goldfinger, M. Wackernagel, M. Stechbart, S. M. Rizk, A. Reed, \& J. Kitzes (Eds.), The ecological footprint atlas 2008, (pp. 1-2). Oakland: Global Footprint Network.

WCED (World Commission on Environment and Development). (1987, December 11). Our common future. Oxford: Oxford University Press. Retrieved from: http://habitat.igc.org/open-gates/wced-ocf.htm, The Concept of Sustainable Development section, 1

Wilks, L., \& Harris, N. (2016). Examining the conflict and interconnectedness of young people's ideas about environmental issues, responsibility and action. Environmental Education Research., 22(5), 683-696.

\section{Publisher's Note}

Springer Nature remains neutral with regard to jurisdictional claims in published maps and institutional affiliations.

\section{Submit your manuscript to a SpringerOpen ${ }^{\circ}$ journal and benefit from:}

- Convenient online submission

- Rigorous peer review

- Open access: articles freely available online

- High visibility within the field

- Retaining the copyright to your article

Submit your next manuscript at $\boldsymbol{\nabla}$ springeropen.com 